\title{
Conservation of matrix protein genes in rabies viruses circulating in South Korea since 1999
}

\author{
Young-Ae Lee, Ha-Hyun Kim, Dong-Kun Yang*, In-Soo Cho \\ Viral Disease Research Division, Animal and Plant Quarantine Agency, Ministry of Agriculture, Food and Rural Affair, \\ Gimcheon 39660, Korea
}

(Received: September 15, 2017; Accepted: October 24, 2017)

\begin{abstract}
Rabies virus (RABV) causes a neurological disease in warm-blooded animals that is nearly always fatal. In this study, we analyzed the matrix (M) genes in 10 Korean street RABV strains isolated from two Provinces during 2011-2013. The M genes in these 10 Korean strains were highly conserved during 1999-2013. Phylogenetic analysis revealed they were closely related to the $M$ genes of RABVs isolated in northeastern China. Specific amino acid substitutions were identified in the KRVB1206, KRVF1301, and BV9901PJ strains. However, functional domains, including those involved in virus production and pathogenicity, were conserved in all 10 strains.
\end{abstract}

Keywords: genetic distance, phylogeny, rabies virus, viral matrix proteins

Rabies virus (RABV) causes a fatal neurological disease in warm-blooded animals, including humans. According to the World Health Organization, rabies infections are responsible for approximately 55,000 human deaths worldwide [12]. Since the first RABV infection was reported in South Korea in 1907, rabies cases have continued to occur nationwide. With the application of an effective RABV vaccine, the number of rabies infections decreased gradually, with no reports of rabies in animals between 1985 and 1992 [9]. However, after a recurrence of rabies in 1993, animal rabies cases have been reported annually in two Provinces. Newly 11 rabies cases were reported in the southern region (Suwon and Hwaseong cities) of Gyeonggi Province between 2012 and 2013 [11].

RABV belongs to the genus Lyssavirus and family Rhabdoviridae and has approximately $12 \mathrm{~kb}$ of unsegmented negative-stranded RNA that encodes the nucleoprotein $(\mathrm{N})$, phosphoprotein $(\mathrm{P})$, matrix $(\mathrm{M})$ protein, glycoprotein $(\mathrm{G})$, and polymerase (L). Among the five structural proteins of $\mathrm{RABV}$, the $\mathrm{M}$ protein is a small protein that forms oligomers that bind to the nucleocapsid periphery to retain the rigidity of the virion structure [5]. Moreover, the M protein plays multifunctional roles in viral transcription, replication, and assembly/budding of RABV [3, 4]. Note that the M protein is a potent modulator of apoptosis after infection because it induces mitochondrial dysfunction, and it acts as a major inducer of apoptosis in neuronal cells [6, 8]. Recently the $\mathrm{RABV} M$ protein was revealed as a modulator of nuclear

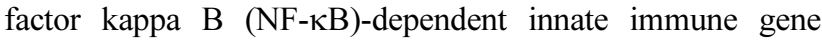
expression [1]. In addition, the RABV-based vaccine lacking the $\mathrm{M}$ protein was deficient in replication and demonstrated improved vaccine efficacy [10]. Therefore, analysis of the M protein in recent Korean street RABVs may be informative for understanding the molecular epidemiology of Korean RABV. Although the N, P, G, and L proteins have been studied in Korean RABVs, the $M$ genes require further investigation. In the present study, we analyzed the $M$ genes of the 10 Korean street RABVs detected in 2011-2013 to identify their characteristics.

The $\mathrm{M}$ genes of the 10 Korean street RABVs were collected from positive brain samples from cattle (KRVB1103, KRVB1104, KRVB1206, and KRVB1302), raccoon dogs (KRVR1202 and KRVR1207), cat (KRVF1301), and dogs (KRVC1303, KRVC1304, and KRVC1305) in 2011-2013 in Gangwon and Gyeonggi Provinces (Table 1). Three previously identified Korean street RABVs (IBV9901PJ/Gyeonggi/1999, BD0406CC/Gangwon/2004, and 08F40/Gangwon/ 2008) from National Center for Biotechnology Information GenBank (USA) were used as references. Reverse transcription-polymerase chain reaction (RT-PCR) for the $M$ gene was performed using specific primers (forward: 5'-ACATGAAAAAAACAGGCAAC-3', reverse: 5'-AGAGGTAAACAAGTGATAAA-3'). The RT-PCR products were purified and ligated with the pGEM-T Easy Vector Systems (Promega, USA). Plasmid DNA was isolated from amplified Escherichia coli (DH5 $\alpha$; Yeastern Biotech, Taiwan), and DNA sequenc-

*Corresponding author

Tel: +82-54-912-0785, Fax: +82-54-912-0812

E-mail: yangdk@korea.go.kr 
Table 1. Korean rabies virus (RABV) isolates used in this study

\begin{tabular}{cccc}
\hline \hline Designation & Origin & Year & Region \\
\hline KRVB1103 & Cattle & 2011 & Gangwon, Goseong \\
KRVB1104 & Cattle & 2011 & Gangwon, Goseong \\
KRVR1202 & Raccoon dog & 2012 & Gangwon, Goseong \\
KRVB1206 & Cattle & 2012 & Hwaseong, Gyeonggi \\
KRVR1207 & Raccoon dog & 2012 & Hwaseong, Gyeonggi \\
KRVF1301 & Cat & 2013 & Hwaseong, Gyeonggi \\
KRVB1302 & Cattle & 2013 & Hwaseong, Gyeonggi \\
KRVC1303 & Dog & 2013 & Hwaseong, Gyeonggi \\
KRVC1304 & Dog & 2013 & Hwaseong, Gyeonggi \\
KRVC1305 & Dog & 2013 & Hwaseong, Gyeonggi \\
\hline
\end{tabular}

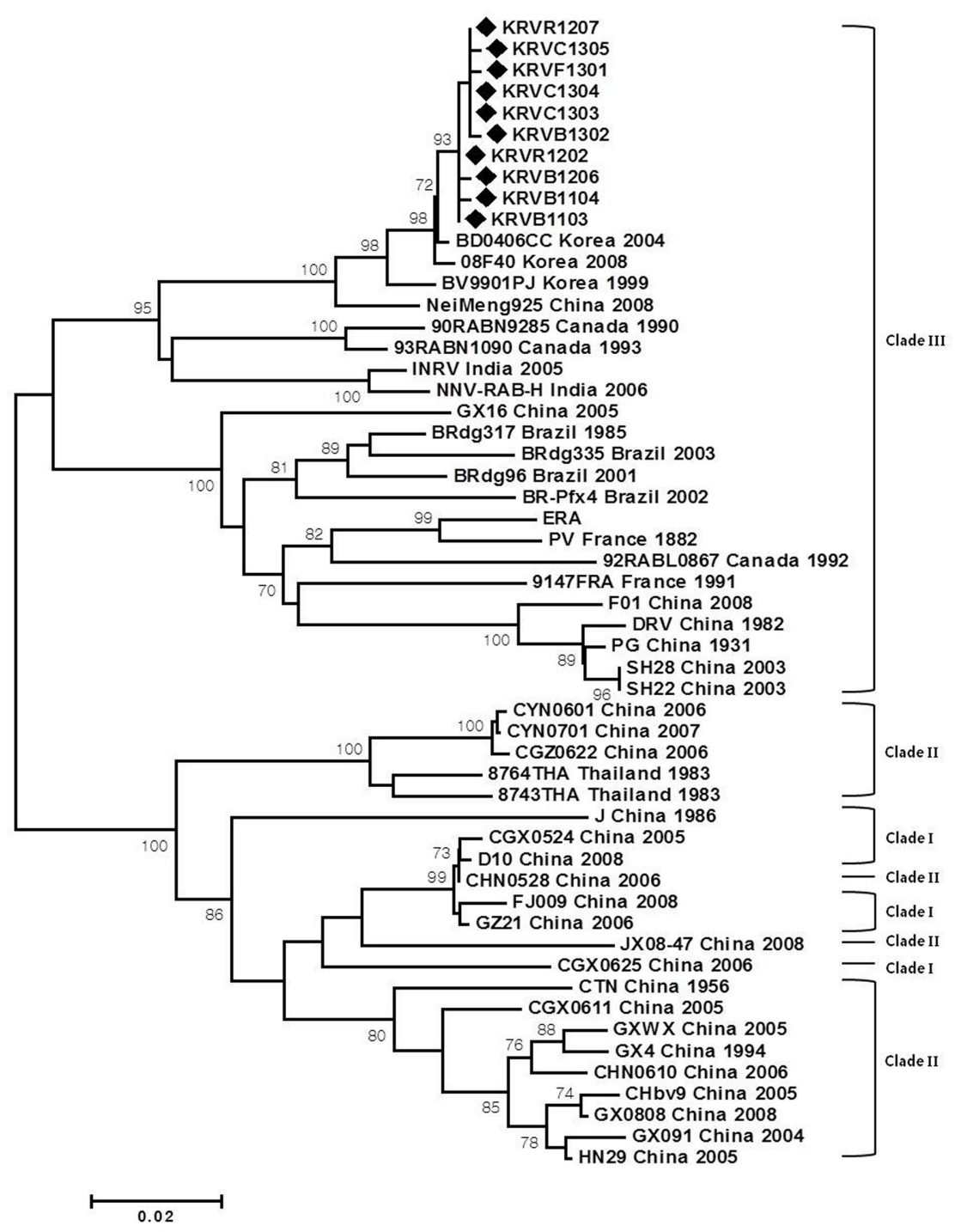

Fig. 1. Phylogenetic analysis of Korean RABV matrix protein (M) genes compared to various reference sequences isolated from other countries. The Korean RABV M genes were classified into Clade III and showed close relationships with those from northeastern China.

ing of the purified plasmids was performed using an automated ABI 3730xl DNA Analyzer (Applied Biosystems, USA).
Genetic distances for phylogenetic analyses were calculated using the Kimura- 2 correction parameter at the nucle- 


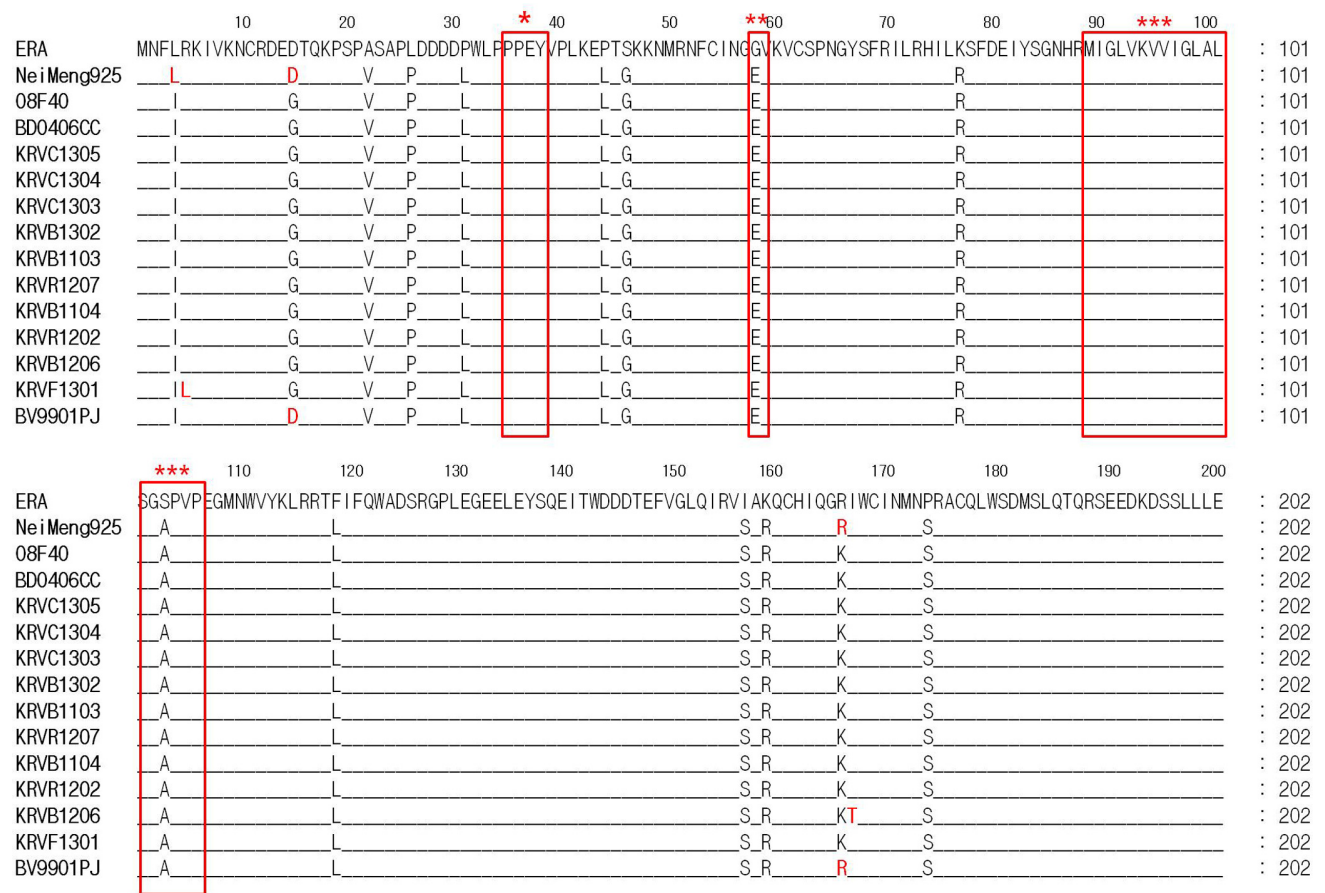

Fig. 2. A comparison of $M$ gene sequences from Chinese RABV (NeiMeng925) and Korean animal vaccine strain ERA (AB781935) revealed 17 amino acid (aa) substitutions. Specific substitutions among Korean RABVs were found at aas I168T of KRVB1206, R5L of KRVF1301, and G15D and K167R of BV9901PJ. The single asterisk (*) indicates the PPxY motif (aa 35-38). The double asterisks (**) indicate E58 critical for viral RNA synthesis. Triple asterisks (***) indicate the hydrophobic domain (aa 89-107). The functional domains essential for virus production and pathogenicity were conserved in the Korean street RABVs.

otide (nt) level using MEGA6. The phylogenetic tree was constructed using the neighbor-joining method with 1,000 bootstrap replicates. The nt and amino acid (aa) sequence similarities were analyzed using the homology and distance matrices method of DNAMAN (ver. 7.0; Lynnon, Canada).

The nt and aa sequence similarities of 609 nt (202 aa) among $10 \mathrm{M}$ genes from recent Korean street RABVs were $99.5-100 \%$ and $99-100 \%$, respectively. In addition, the $10 \mathrm{M}$ genes had $97.9-99.5 \%$ nt similarity and $98.5-100 \%$ aa similarity compared to three RABV M genes (lBV9901PJ, BD0406CC, and 08F40) reported previously (data not shown). These results indicate that the $\mathrm{M}$ genes of these Korean street RABVs had minor mutations and were highly conserved from 1999 to 2013. Seven M genes from Gyeonggi Province between 2012 and 2013 had higher similarity (99.0-99.3\%) to those from the Gangwon Province (BD0406CC/Gangwon/ 2004 and 08F40/Gangwon/2008) than those (97.9-98\%) isolated earlier from the Gyeonggi Province (BV9901PJ/Gyeonggi/1999; data not shown). These results coincide with results from a previous study that investigated the $\mathrm{N}$ and $\mathrm{G}$ genes of RABV [11].

Phylogenetic analysis revealed that the 10 Korean street RABV $M$ gene nt sequences were closer to the RABVs of Gangwon Province (BD0406CC and 08F40) than Gyeonggi Province (BV9901PJ). A comparison with various reference sequences from other countries led to the classification of
Korean RABV M genes into Clade III, which comprises arctic-related variants from Asia, the Americas, and Europe (previously categorized into Clades I-III) [13]. Specifically, the 10 Korean street RABV isolates were closest to one RABV isolated from China (NeiMeng925) among the reference strains (Fig. 1). These results indicate that the 10 Korean street $\mathrm{RABV}$ isolates have a close phylogenetic relationship with RABVs of northeastern China, showing results similar to those from a previous study with $\mathrm{N}$ and $\mathrm{G}$ genes [14].

A comparison of the recent Korean street RABV isolates and the ERA strain (AB781935), which was used to generate the rabies vaccine in South Korea, revealed 17 aa substitutions (Fig. 2). A comparison of the Korean RABVs and a Chinese RABV (NeiMeng925) revealed three substitutions at aas I4L, G15D, and K166R. Specific differences among the Korean RABVs were found at aas I168T of KRVB1206, R5L of KRVF1301, and G15D and K167R of BV9901PJ (Fig. 2). The hydrophobic domain (residues 89-107, MIGLV KVVIGLALSGAPVP), which interact with the membrane lipids of host cells, was conserved in the Korean street RABVs (Fig. 2) [2]. The Korean street viruses contained the PPEY consensus sequence (aas 35-38) of the PPxY motif, which is essential for virus budding and interaction with the WW domains of cellular components (Fig. 2) [7]. Residue E58, which is critical for viral RNA synthesis, was also conserved in the Korean street viruses (Fig. 2) [3]. It appears that 
these Korean street RABVs have the ability to downregulate transcription and to stimulate replication normally.

The Korean RABV M genes that were highly conserved from 1999 to 2013 were classified into Clade III, which comprises arctic-related variants from Asia, the Americas, and Europe [13]. Korean RABV M genes were closer to those of RABVs isolated in northeastern China, showing results similar to those found for $\mathrm{N}$ and $\mathrm{G}$ genes [14]. Seven Korean RABV M genes isolated from Gyeonggi Province were more similar to those from Gangwon Province than to $M$ genes from Gyeonggi Province reported in a previous study [11]. Specific aa substitutions in the $M$ genes were found in KRVB1206, KRVF1301, and BV9901PJ isolates. Functional domains essential for virus production and pathogenicity were conserved in the Korean street RABVs.

\section{Acknowledgments}

This work was supported financially by a grant (B1543083-2016-17-01) from the Animal and Plant Quarantine Agency, Republic of Korea.

\section{References}

1. Ben Khalifa $\mathbf{Y}$, Luco $\mathbf{S}$, Besson B, Sonthonnax $\mathbf{F}$, Archambaud M, Grimes JM, Larrous F, Bourhy H. The matrix protein of rabies virus binds to RelAp43 to modulate NF-kB-dependent gene expression related to innate immunity. Sci Rep 2016, 6, 39420.

2. Capone J, Ghosh HP. Association of the nucleocapsid protein $\mathrm{N}$ of vesicular stomatitis virus with phospholipid vesicles containing the matrix protein $\mathrm{M}$. Can $\mathrm{J}$ Biochem Cell Biol 1984, 62, 1174-1180.

3. Finke S, Conzelmann KK. Dissociation of rabies virus matrix protein functions in regulation of viral RNA synthesis and virus assembly. J Virol 2003, 77, 12074-12082.

4. Finke S, Mueller-Waldeck R, Conzelmann KK. Rabies virus matrix protein regulates the balance of virus transcription and replication. J Gen Virol 2003, 84, 1613-1621.

5. Ge P, Tsao J, Schein S, Green TJ, Luo M, Zhou ZH. Cryo-EM model of the bullet-shaped vesicular stomatitis virus. Science 2010, 327, 689-693.

6. Gholami A, Kassis R, Real E, Delmas O, Guadagnini S, Larrous F, Obach D, Prevost MC, Jacob Y, Bourhy H. Mitochondrial dysfunction in lyssavirus-induced apoptosis. J Virol 2008, 82, 4774-4784.

7. Irie T, Licata JM, McGettigan JP, Schnell MJ, Harty RN. Budding of PPxY-containing rhabdoviruses is not dependent on host proteins TGS101 and VPS4A. J Virol 2004, 78, 2657-2665.

8. Kassis R, Larrous F, Estaquier J, Bourhy H. Lyssavirus matrix protein induces apoptosis by a TRAIL-dependent mechanism involving caspase-8 activation. J Virol 2004, 78, 6543-6555.

9. Kim CH, Lee CG, Yoon HC, Nam HM, Park CK, Lee JC, Kang MI, Wee SH. Rabies, an emerging disease in Korea. J Vet Med B Infect Dis Vet Public Health 2006, 53, 111-115.

10. McGettigan JP, David F, Figueiredo MD, Minke J, Mebatsion T, Schnell MJ. Safety and serological response to a matrix gene-deleted rabies virus-based vaccine vector in dogs. Vaccine 2014, 32, 1716-1719.

11. Oem JK, Kim SH, Kim YH, Lee MH, Lee KK. Reemergence of rabies in the southern Han river region, Korea. J Wildl Dis 2014, 50, 681-688.

12. World Health Organization (WHO). WHO expert committee on rabies. World Health Organ Tech Rep Ser 1992, 824, 184.

13. Wu H, Wang L, Tao X, Li H, Rayner S, Liang G, Tang Q. Genetic diversity and molecular evolution of the rabies virus matrix protein gene in China. Infect Genet Evol 2013, 16, 248-253.

14. Yang DK, Park YN, Hong GS, Kang HK, Oh YI, Cho SD, Song JY. Molecular characterization of Korean rabies virus isolates. J Vet Sci 2011, 12, 57-63. 